\title{
Interaction analysis of waffle slabs supporting houses on expansive soil
}

\author{
Mohammad Fardipour ${ }^{1}$ Emad Gad ${ }^{1}$ Siva Sivagnanasundram ${ }^{2}$. \\ Pathmanathan Rajeev $^{1} \cdot$ Aruna Karunarathne $^{1} \cdot$ John Wilson $^{1}$
}

Received: 13 March 2016/ Accepted: 21 June 2016/Published online: 6 July 2016

(c) Springer International Publishing Switzerland 2016

\begin{abstract}
This study investigates the soil-slab interaction for waffle slabs supporting residential structures on highly expansive soils. Interaction modelling techniques are reviewed, and the implications of the modelling assumptions typically employed are discussed. More realistic modelling assumptions are proposed, and their effects are investigated. For this purpose, advanced incremental/ inelastic FE models are developed in OpenSees to capture the slab structural response during the history of soil movement in heave condition. Soil profile (mound shape), soil stiffness profile and soil-slab contact are updated corresponding to growing mound. The study provides an insight into the resulting changes in bending moment and deformation demands on such slabs. It is found that the conventional assumption of a constant soft soil stiffness coupled with a stepped transition to that of hard soil is generally unconservative. The analyses also suggest that
\end{abstract}

Mohammad Fardipour

mfardipour@swin.edu.au

Emad Gad

egad@swin.edu.au

Siva Sivagnanasundram

ssiva@powercor.com.au

Pathmanathan Rajeev

prajeev@swin.edu.au

Aruna Karunarathne

akarunarathne@swin.edu.au

John Wilson

jwilson@swin.edu.au

1 Department of Civil and Construction Engineering, Faculty of Science, Engineering and Technology, Swinburne University of Technology, Hawthorn, Victoria, Australia

2 Powercor Network Services, Hawthorn, Australia predefining a critical scenario and disregarding the history of loading is not necessarily conservative.

Keywords Residential slabs and footings - Expansive soil · Waffle slab · Soil-structure interaction · Soil stiffness · Inelastic/incremental FE modelling · OpenSees

\section{Introduction}

Raft foundations (waffle raft/stiffened raft with or without deep edge beam) are commonly used, in a number of places around the world, as the preferred foundation system for supporting structures. In Australia, waffle rafts are commonly constructed to support relatively light residential structures (houses).

Slabs are primarily designed to limit the differential movement of the structure considering the gravity loads that need to be safely transferred to ground and also the potential movements of underneath reactive soil. Reactive soil can swell/shrink with changes in moisture content, and this could happen due to several reasons, including: (1) seasonal/natural causes, such as rain, evaporation, and effect of adjacent trees; and (2) other causes, such as pipe leakage, poor or faulty drainage systems, and poor surface water management during and after construction.

In Australia, AS2870-2011 [1] is the relevant standard for analysis, design and construction of residential slabs and footings. Unfortunately, there have been some recent reports of damages to hundreds of houses supported by waffle slabs (designed to AS2870) on highly reactive soils of Western suburbs of Melbourne, Victoria, Australia. Site investigations have confirmed excessive slab differential movements as being responsible for reported 
cracking and damages to houses beyond their serviceability limits. This study investigates some relevant aspects of current design practice and philosophy with the focus on soil-slab interaction analysis and the performance of waffle slabs.

\section{Background of soil-slab interaction}

Soil-slab interaction is traditionally modelled using the 'beam on mound model' as pioneered by Lytton [2]. The 'beam' is usually a strip of slab of unit width with average (or smeared) strength, stiffness and contact properties of the actual slab. The 'mound' represents the fully developed shape of covered but unloaded ground (representing the covering effect of slab). The problem is typically subdivided into two distinguished boundary conditions, namely, the 'edge heave' and 'edge settlement'.

The elegant beam on mound model as proposed by Lytton comprised of the assumptions of a rigid beam resting on a parabolic mound, as shown in Fig. 1a. Length $X$ or 'liftoff point' could be calculated based on equilibrium of applied loads and resulting soil reaction (calculated as the product of soil stiffness $K$ by the area of the depressed soil as shaded ' $A$ ' in this figure). Estimated $X$ value could then be used to calculate the centroid of the depressed mound (located at $3 X / 8$ ) and to estimate the moment required at the critical location of the beam which was typically assumed to be at mid-span.

Following the Lytton's model, soil-slab interaction modelling has been the subject of a number of refinements over the past decades. This was mainly focused on

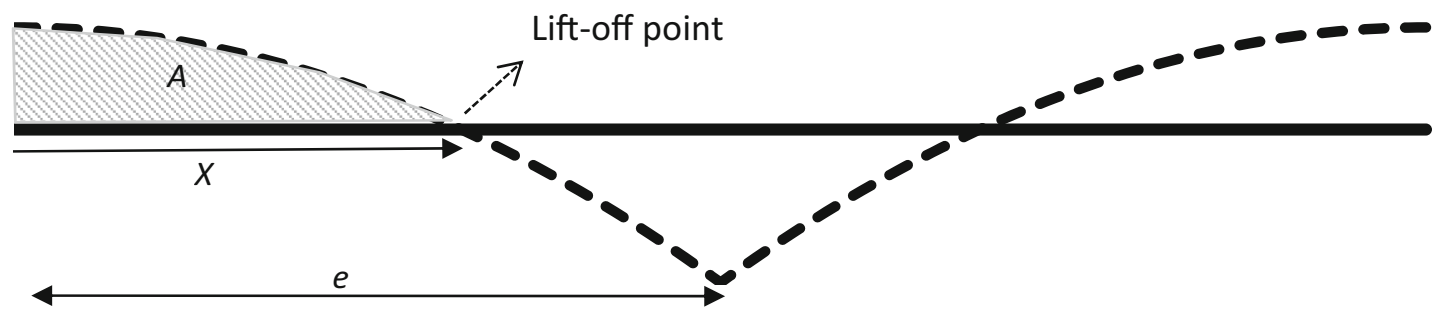

(a) Lytton Model (rigid beam)

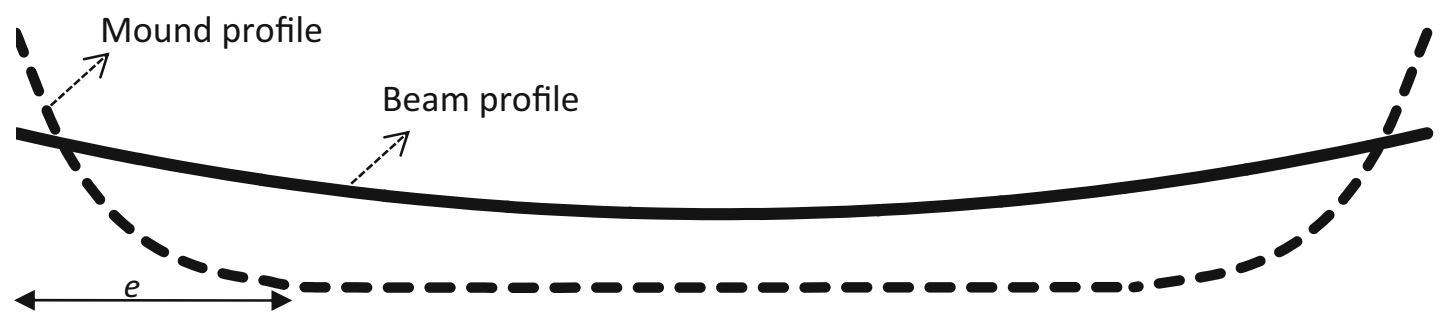

(b) Mitchell Model (beam of assumed profile)

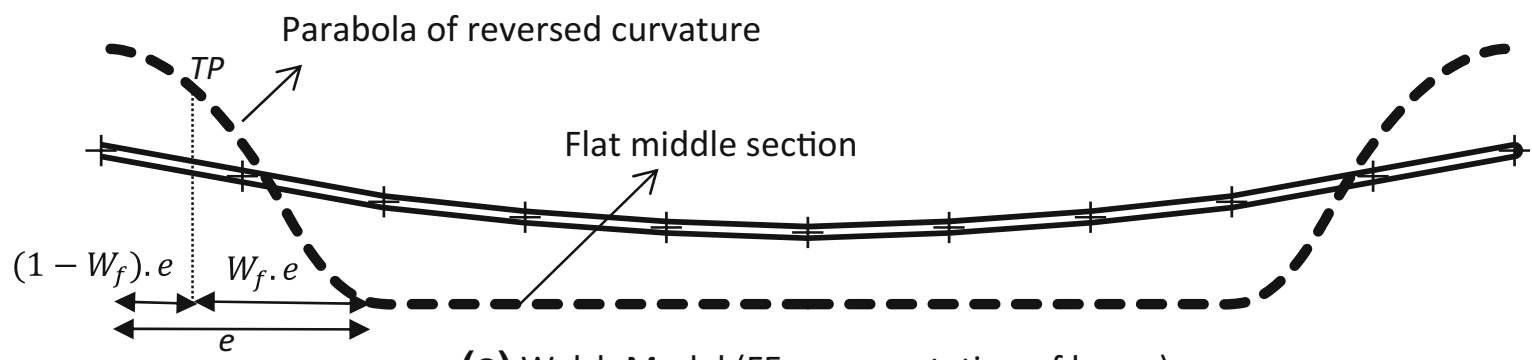

(c) Walsh Model (FE representation of beam)

Fig. 1 a Lytton model is a rigid beam on parabolic mound; b Mitchell model includes predefined polynomials for beam and mound; and c Walsh's model is based on parabolas of reversed curvature and FE representation of beam 
the attempts for more realistic representation of the beam and the mound recognising the sensitivity of analyses to these parameters particularly in the case of edge heave condition.

Mitchell [3] originally proposed a predefined profile of polynomial shape for the beam and also a second polynomial of exponent ' $m$ ' to represent a refined mound shape of shorter edge distance (e). (see Fig. 1b). His model is recommended in AS 2870-11 with provisions to estimate the mound exponent $(\mathrm{m})$.

Walsh and Cameron [4] used finite-element modelling to represent the beam with a technique to update the flexural stiffness of each beam element with increasing moment developed in the element. In the model, they used classical Winkler springs to represent the soil response, coupled with the concept of co-operative width to consider the contribution of soil shear resistance. In this model, the mound shape had some changes before taking the current shape as could be seen in Fig. 1c which is also adopted by AS2870-11. The profile comprises a flat middle section and two parabolas of reversed curvature defined over each edge. The joining or turning point of parabolas (TP) is stipulated to be at a distance of $\left(W_{f} . e\right)$ away from each end of the middle section, where $W_{f}$ is a shape factor depending on the magnitude of the characteristic soil movement $\left(Y_{s}\right)$. A detailed account of the history of mound development and proposed amendments to the current shape factor can be found in a recent study by Payne and Cameron [5].
Mitchell and Walsh models are of particular attention in this study as they are recommended as acceptable methods of interaction analysis in AS2870-11.

\section{Assumptions inherent in current soil-slab interaction models}

In the models outlined above, there are a few commonly used assumptions for edge heave condition which include the following:

1) A uniform soft soil stiffness of $1 \mathrm{MPa} / \mathrm{m}$ is typically assumed over the edge distances.

2) The transition from soft soil stiffness to hard soil stiffness (usually taken as $K_{h}=5 \mathrm{MPa} / \mathrm{m}$ over the middle section of the slab) is abrupt. In other words, a 'step stiffness profile' is assumed.

3) The most critical scenario for the slab is taken as when the credible mound is fully developed in height and the magnitude of soil stiffness is reduced to that of soft soil $\left(K_{s}=1 \mathrm{MPa} / \mathrm{m}\right)$.

Figure 2 shows the above assumptions for a given fully developed mound height $\left(Y_{m}=50 \mathrm{~mm}\right)$ and corresponding soil stiffness profile. It is to be noted that such assumptions may be considered gross as in reality, the mound development and soil stiffness reduction are gradual both vertically with increasing the heave height and also horizontally under the slab (see Fig. 3).
Fig. 2 Unique mound and soil stiffness profiles conventionally assumed to develop the most critical demand on a slab
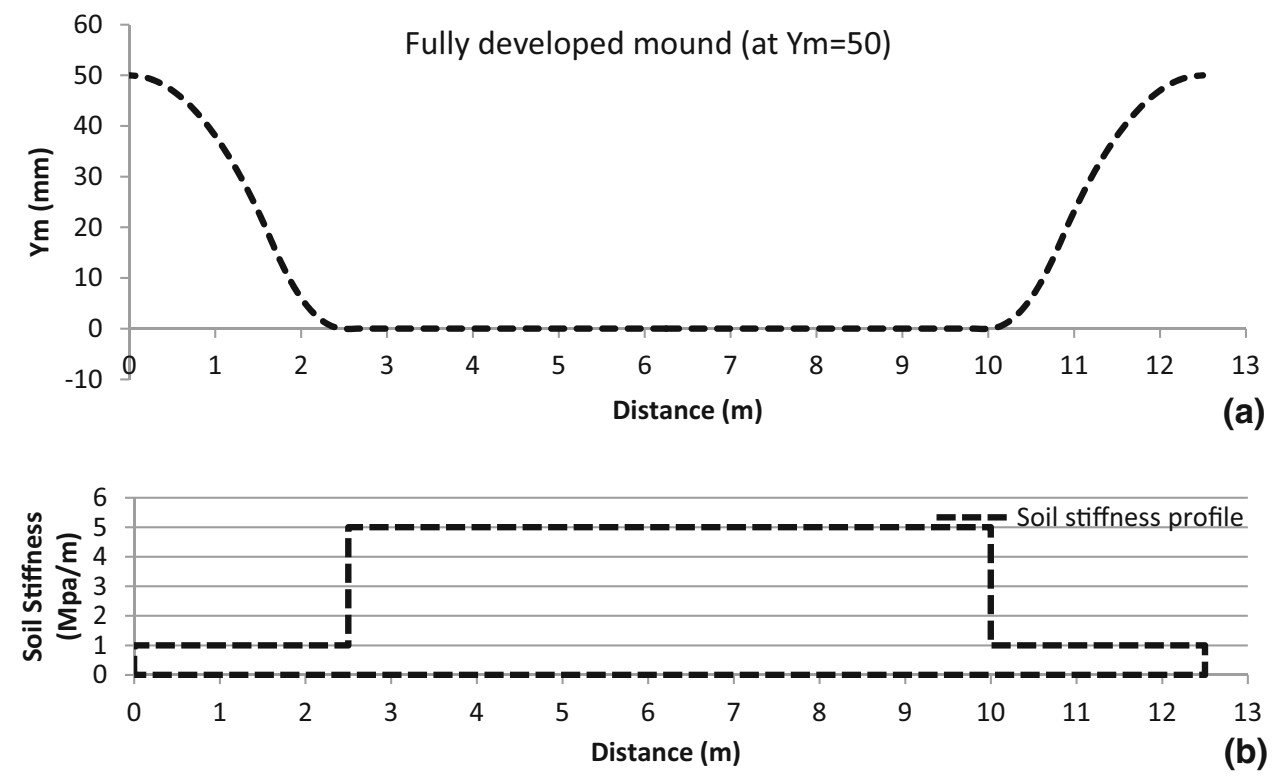
Fig. 3 Mound development and corresponding soil stiffness reduction are gradual

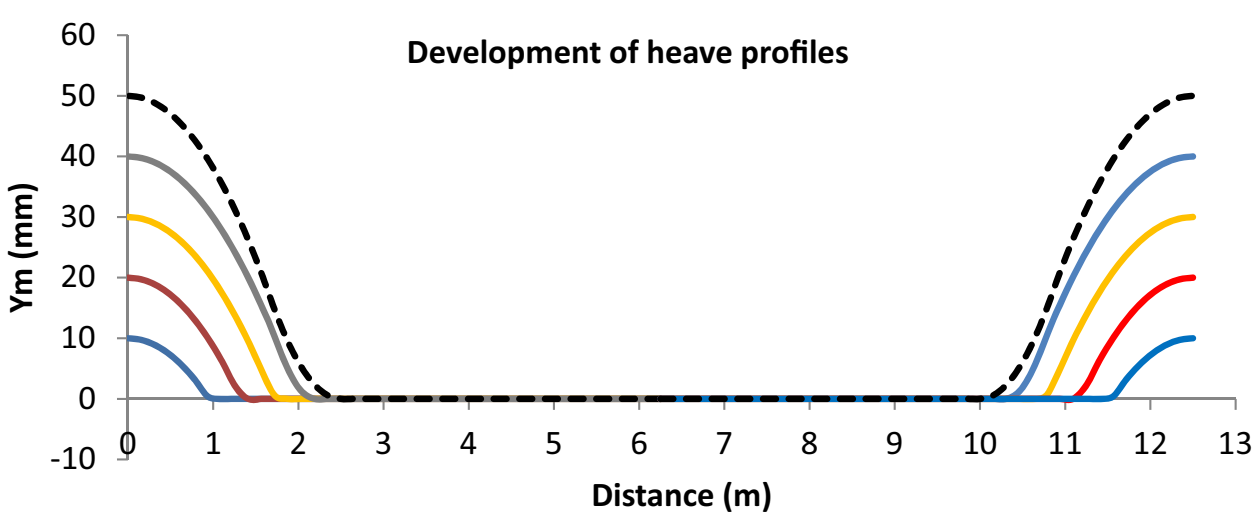

It should be mentioned that, in general, underestimating the soil stiffness could result in un-conservative estimation of bending moment and deformation demands on slabs.

\section{Proposed soil stiffness profile corresponding to developing mound}

Figure 4 shows an intermediate (not final) representation of soil stiffness profiles for a developing mound of increasing height, as shown in Fig. 3. The top diagram, for instance, suggests a uniform soil stiffness of $5 \mathrm{MPa} / \mathrm{m}$ for the heave range of $0<Y<10 \mathrm{~mm}$. The second top profile corresponds to a heave range of $10 \mathrm{~mm}<Y<20 \mathrm{~mm}$ and so on. It is noted that the edge distance $(e)$ grows with the heave height in accordance with the relevant provisions as stipulated in AS2870-11.

Given the potential sensitivity of bending moment and deflection demands on slabs to distribution of soil stiffness within the edge distance, in a heave condition, a more realistic transition of soft to hard soil is additionally considered as can be seen in Fig. 5.

Relevance of linear distribution assumption of soil stiffness may be discussed with reference to Walsh's swellstiffness curves and also considering the laboratory tests conducted at Swinburne University.

Figure 6 shows a typical Walsh's soil swell-stiffness curve in a schematic form [4] in which soil stiffness (represented by the slope of tangents to the curve) increases with decreasing soil swell height (Y). Walsh and Cameron proposed a simplified two-stage representation of soil response by considering the tangents corresponding to the soft soil (i.e., when $Y=Y_{m}^{s}$ ) and hard soil $Y=Y_{m}^{h}$ only. This study attempts to investigate the implications of adopting a more refined multistage/linear representation of the changes in soil stiffness with swell height as opposed to the two-stage form.
Figure 7 shows the variation of soil stiffness with gravimetric moisture content (GMC) as obtained from the laboratory tests of typical reactive soil/clay of interest which was collected from a monitoring site in one of the western suburbs of Melbourne [6]. The tests/curves were obtained using consolidation and power law [7] methods. A polynomial of the second order was then obtained from the test results as the most relevant curve approximating the soil stiffness across the entire range of moisture content. Taking GMC as a measure of swell, this curve further suggests that a linear variation of stiffness (as opposed to stepped stiffness) could be a simplified yet relevant representation of swelling soil stiffness.

\section{Model development for soil-slab interaction analysis}

Soil-waffle slab interaction analysis can be conducted using commercial packages, such as CORD (Walsh [8] and SLOG [3]. However, a research tool was needed to allow for:

1) The implementation of refined assumptions regarding the soil stiffness.

2) Simulating the history of loading (soil swelling) to capture the critical 'mound height-soil stiffness' combination ( $Y$ - $K$ combination). The current assumption is that the most critical scenario corresponds to the combination of $Y=Y_{m}$ and $K=1 \mathrm{MPa} / \mathrm{m}$.

3) Investigating the sensitivity of interaction analyses to the assumptions regarding the co-operative width (this will be addressed later in the study).

The required tool was developed for the edge heave condition using OpenSees FE software. The main specifications of the developed FE model (referred herein as Swinburne Model) could be listed as follows: 
Fig. 4 Soil stiffness profiles (stepped) corresponding to a developing mound
Fig. 5 The proposed soil stiffness profiles (with linear transition) corresponding to a developing mound
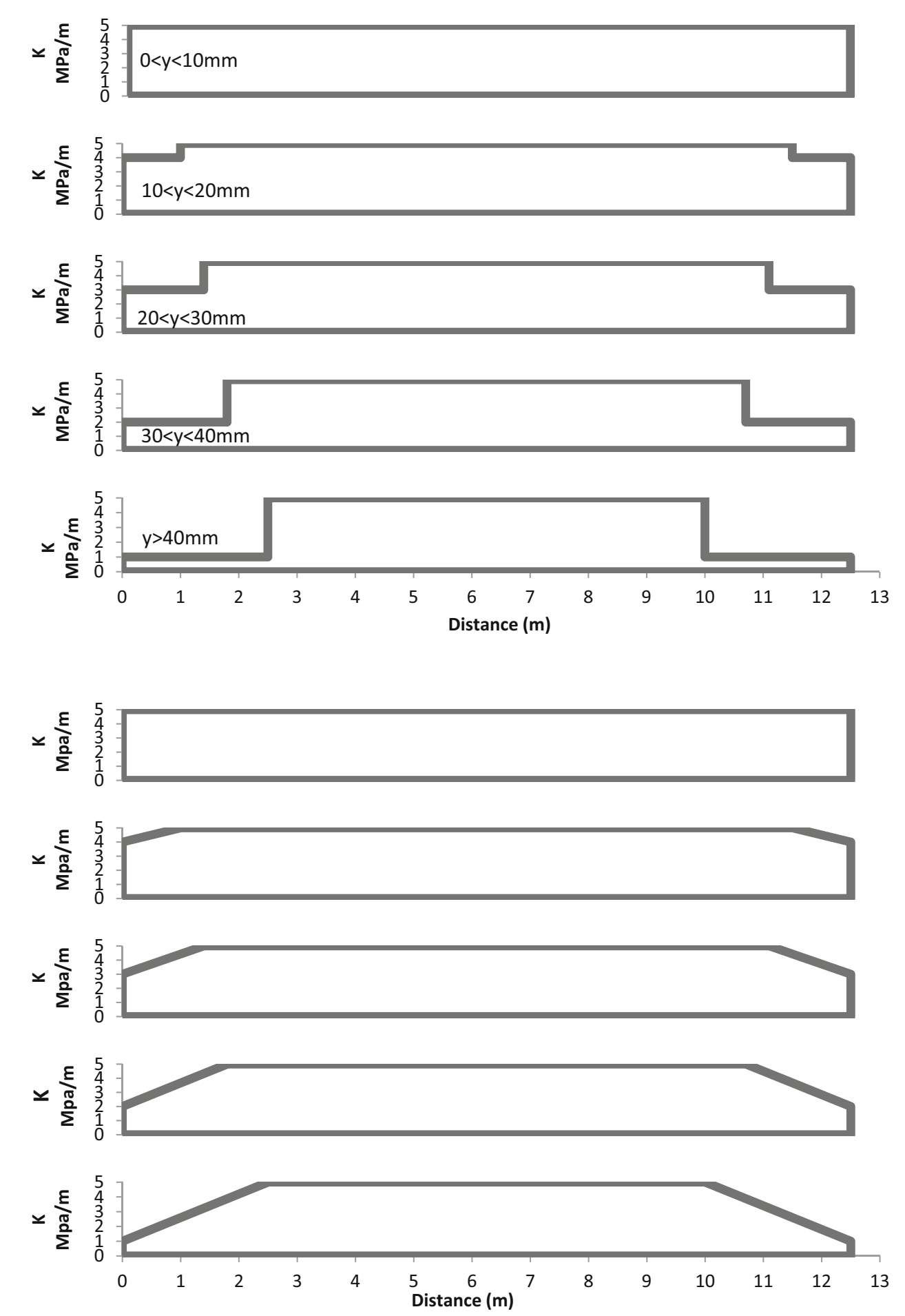

1) Slab is initially assumed to be resting on a flat ground. History of soil swelling is then simulated by modelling the action of expansive soil which pushes against slab in a gradual manner from $Y=0$ to $Y=Y_{m}$

2) The beam is modelled using fibre section finite elements. Non-linear steel and concrete materials were included. The cracking and inelastic flexural responses, at any location along the beam, are captured at each integration point (spaced at about $30 \mathrm{~mm}$ intervals along the beam) through the built-in capacity of fibre elements for moment-curvature analysis.

3) The soil is modelled using the classical Winkler springs and the co-operative width to consider the shear contribution of the soil outside the contact 


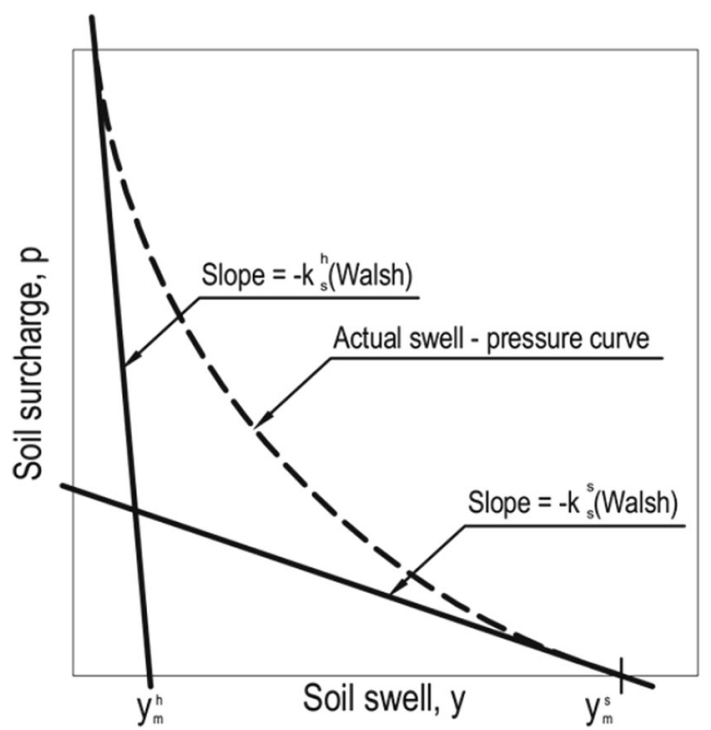

Fig. 6 Soil stiffness (slope of tangent to the curve) increases with reducing swell height (i.e. soil swell)

boundaries. "Zero-Length Elements" and "No Tension Materials" (as available in OpenSees) were employed for this purpose. A special algorism was also developed to monitor and detect the separation of the beam from ground (as the mound height is increased incrementally) and to enforce an updated boundary condition for the beam before the next increment of heaving.

4) The mound profile, magnitude and distribution of soil stiffness were updated with increasing mound height at every 10 -mm heaving intervals (See Figs. 3, 4, 5)

5) A linearised version of the Walsh's mound profile was employed as could be seen in Fig. 8

6) The program was benchmarked against CORD under similar set of assumptions
It should be noted that there are still uncertainties regarding the actual shape of mound profiles as may be inferred from the comparisons of Walsh and Mitchells models, yet both recognised by AS2870-11 (See Fig. 9). This may also be inferred from continuing attempts for refinements of the shape of such profiles, e.g. [5] and the ongoing research at Swinburne University of Technology which is investigating the changing trend of such profiles with prevailing climate condition. Given that, it is believed that the employed simplified mound profiles are reasonably/adequately representative of the two well-known set of profiles. It is noted that Fig. 9 is merely intended to illustrate the extent of variations in currently accepted mound profiles, for a given set of parameters importantly L (slab Length) and Hs (depth of design suction change for Melbourne-AS2870-2011). The curves in Fig. 9 are not used directly in any of the models analysed in this study. Instead, a simplified, yet comparable, version of mound profiles was employed as outlined earlier and shown in Fig. 8.

\section{Discussions on sensitivity analyses}

For the purpose of the intended sensitivity analyses, a square waffle slab of length $L=12.5 \mathrm{~m}$ and depth $D=460 \mathrm{~mm}$ was considered to support a single storey structure of articulated masonry veneer (AMV) on a highly reactive soil (classified as $\mathrm{H} 2$ by AS2870-11). Analysed cross section, dimensions and reinforcements were as shown in Fig. 10. The concrete compressive strength and steel yield strength were 20 and $500 \mathrm{MPa}$, respectively. The edge line load and the uniformly distributed load were estimated to be $\mathrm{ELL}=9.5 \mathrm{kN} / \mathrm{m}$ and $\mathrm{UDL}=6.5 \mathrm{kPa}$, respectively. The employed UDL value is a typical design distributed load which considers the self-weight of slab,
Fig. 7 Taking the GMC as a measure of soil swell, assumed linear changes in soil stiffness is suggested by the polynomial curve

\section{E function- Braybrook}

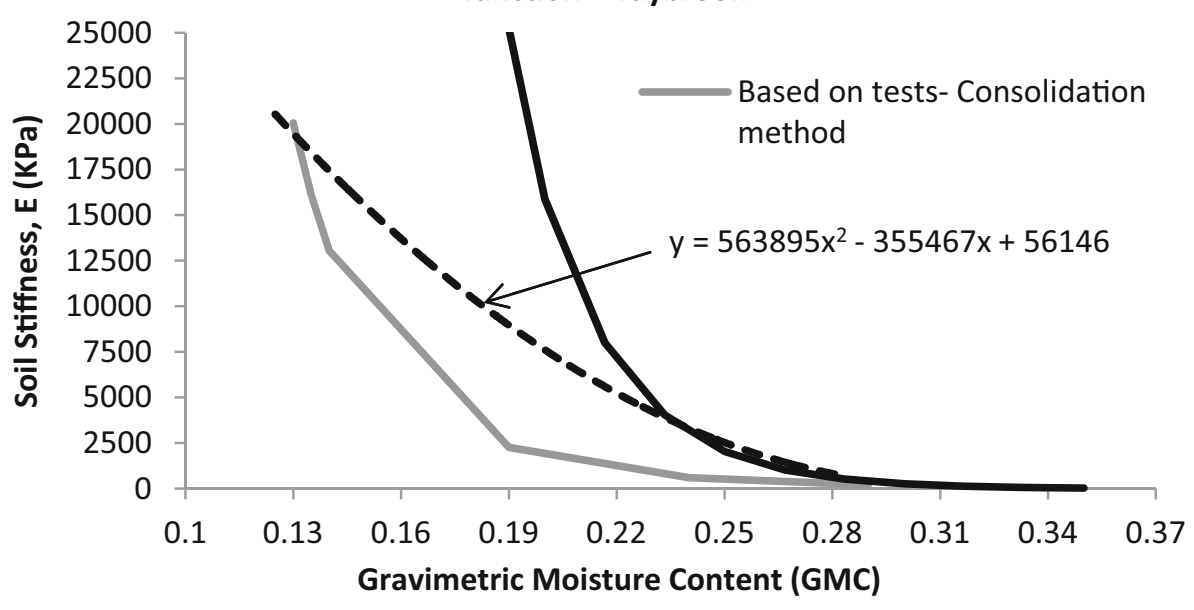




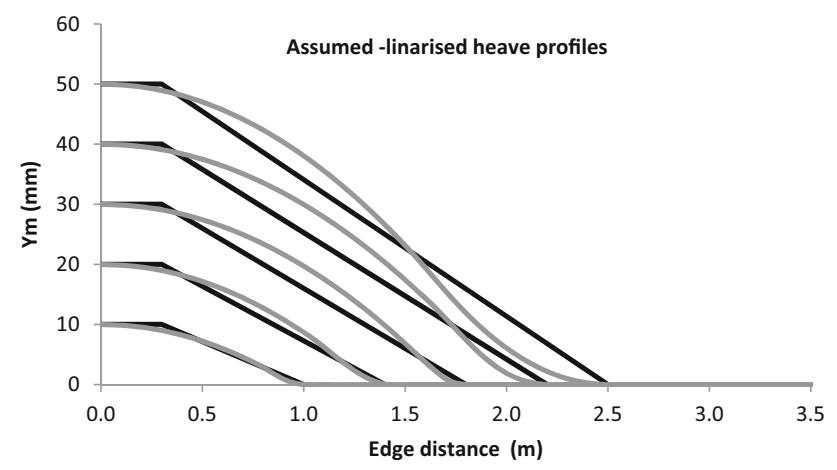

Fig. 8 Simplified version of Walsh's mound profile were employed in this study

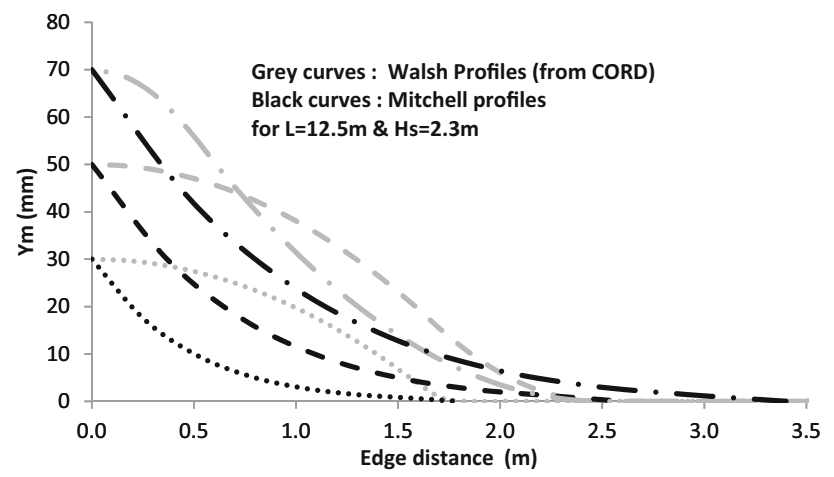

Fig. 9 Two possible assumed soil shapes for edge heave

live load, and so on. Yield moment capacity of the section was found using a separate spread sheet-based inelastic moment-curvature analysis program to be $\left(M_{y}=40-42 \mathrm{kN} \mathrm{m}\right)$.

The slab shown above was first analysed using CORD and SLOG for the edge heave condition. The limiting $Y_{m}$ values and corresponding moment demands $M_{\text {req }}$ were recorded, as tabulated in Table 1 . The slab differential deflection limit was taken as recommended by AS2870-11 (i.e. $\Delta=30 \mathrm{~mm}$ ) for the considered slab/structural type. Swinburne FE model was then used in the following five model cases:

Model\#1 Conventional case. In other words, a constant soft soil stiffness of $1 \mathrm{MPa} / \mathrm{m}$ over the edge was assumed (regardless of the mound height) with a stepped transition to that of hard soil $(5 \mathrm{MPa} / \mathrm{m})$.

Model\#2 Magnitude of the soft soil over the edge is uniformly reduced from 5 to $1 \mathrm{MPa} / \mathrm{m}$ with increasing mound height from 10 to $50 \mathrm{~mm}$. The assumption of step transition from the soft to hard soil is still maintained in this model, as shown in Fig. 4. This is an intermediate model to demonstrate the effect of history of loading.

Model\#3 Magnitude of soil stiffness is dependent on the mound height at the edge (similar to Model\#2) plus a linear transition/distribution from soft to hard soil, as shown in Fig. 5.

Model\#4 This model parameterises the effect of soil shear deformation on overall foundation stiffness through a concept known as "co-operative width" as introduced by Walsh and Cameron [4]. Walsh and Cameron proposed that in a simple spring model representing foundation, the extra stiffness of foundation associated with soil shear deformation can be represented by an extra $(200 \mathrm{~mm})$ length or width of footing at the locations where there is a contact discontinuity. Walsh assumed that the discontinuity between soil (foundation) and slab (footing) occurs merely outside the boundary of slab and hence included singlesided 200-mm co-operative width for the edge beams only (see Fig. 11a). This assumption was employed in Models $1-3$, but it is refined in Model 4 which considers the cooperative width for both internal and edge beams in waffle slabs (see Fig. 11b).

Model 4 is intended to demonstrate that underestimating the effective contact area between ground and slab could be translated into more soil depression, for a given heave
Fig. 10 standard section and reinforcing details as analysed in this study. All dimensions are in millimetre

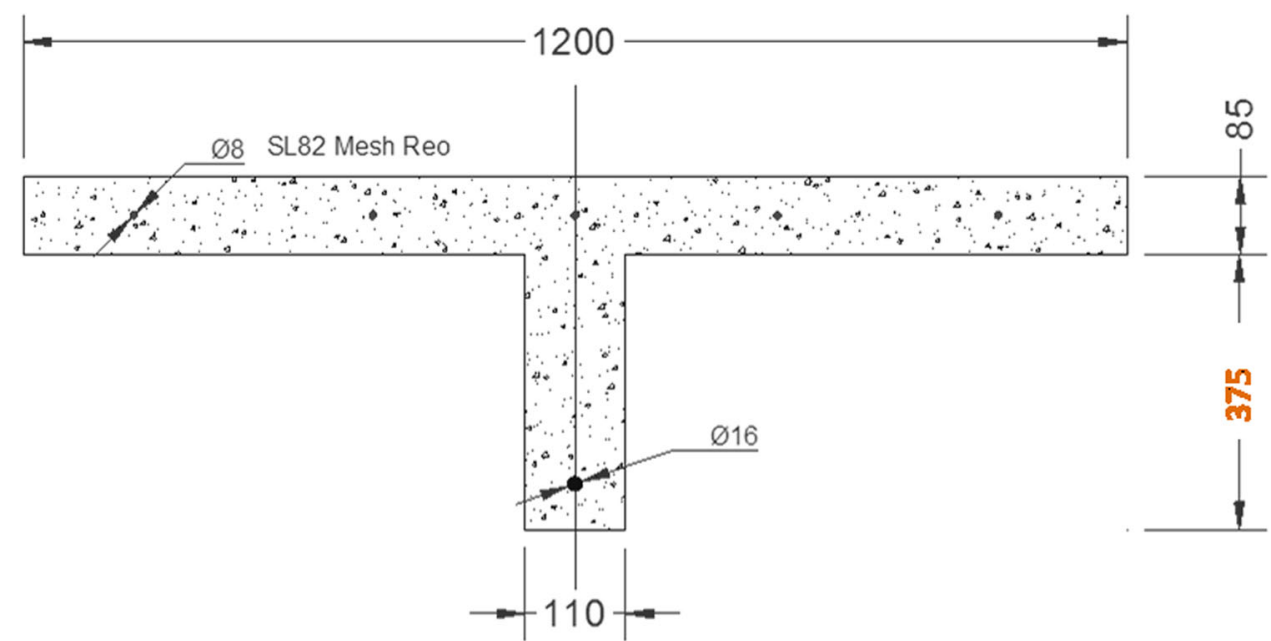


Table 1 Limiting Ym as obtained from CORD, SLOG and Swinburne model for the analysed slab

\begin{tabular}{lll}
\hline Method/Software & $\begin{array}{l}\text { Limiting Ym for edge } \\
\text { heave only }(\mathrm{mm})\end{array}$ & $\begin{array}{l}\text { Required } \\
\text { Moment }(\mathrm{kN} \mathrm{m})\end{array}$ \\
\hline CORD & 41 & 22 \\
Swinburne (Model 1) & $56^{\mathrm{a}}$ & 32 \\
SLOG & 82 & 29
\end{tabular}

This table excludes further limitations of Ym corresponding to edge settlement. The results are very sensitive to inputs and one should not generalise the figures shown in this table

${ }^{a}$ This limit was decided based on the consideration of factored yield capacity $\left(0.8 M_{y}=32 \mathrm{kNm}\right)$ which is a more notional than real failure limit
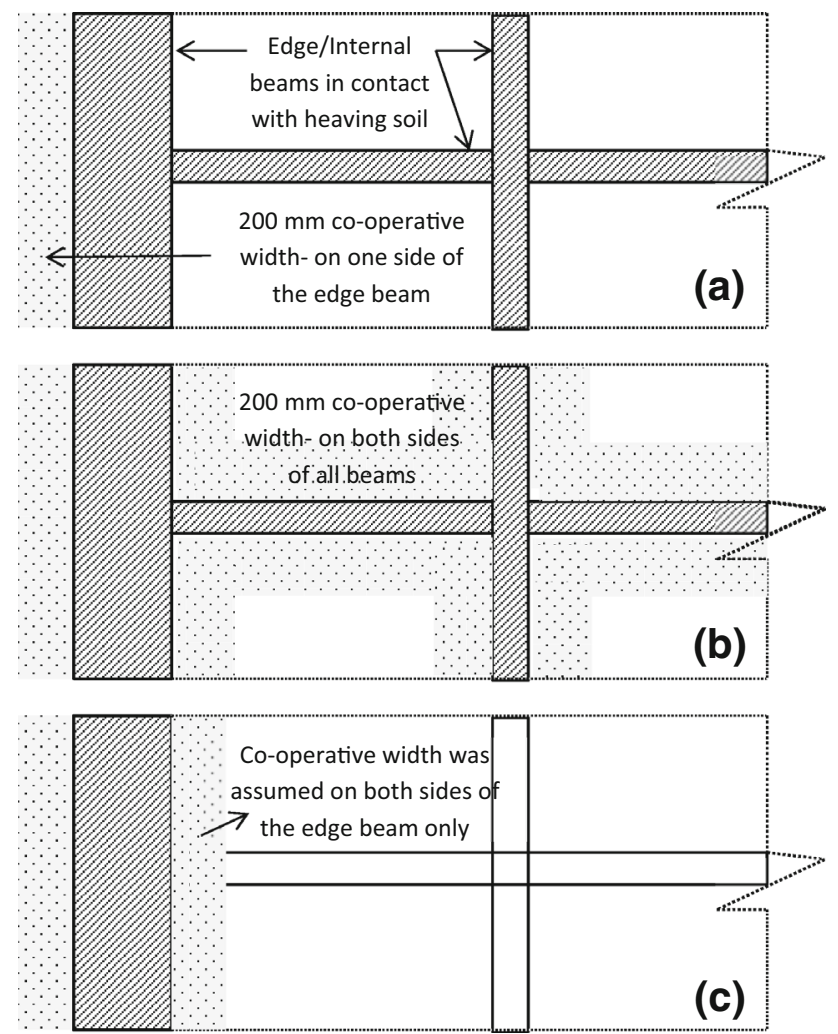

Fig. 11 Top view of soil-slab contact; effective contact area a corresponding to Models $1-3$; b corresponding to Model 4 and c edge heave assumption corresponding to Model 5

magnitude, and less deformation demand on slab which is unconservative.

Model\#5 This model is similar to Model 2 except that only the soil underneath of the edge beam is heaving (see Fig. 11c) to simulate a case of concentrated heave that may occur due to causes other than seasonal/uniform moisture change (e.g. pipe leakage).

Figures 12 and 13 show the deflection profiles and bending moment diagrams, respectively, corresponding to the first four models developed. Considering the 30-mm

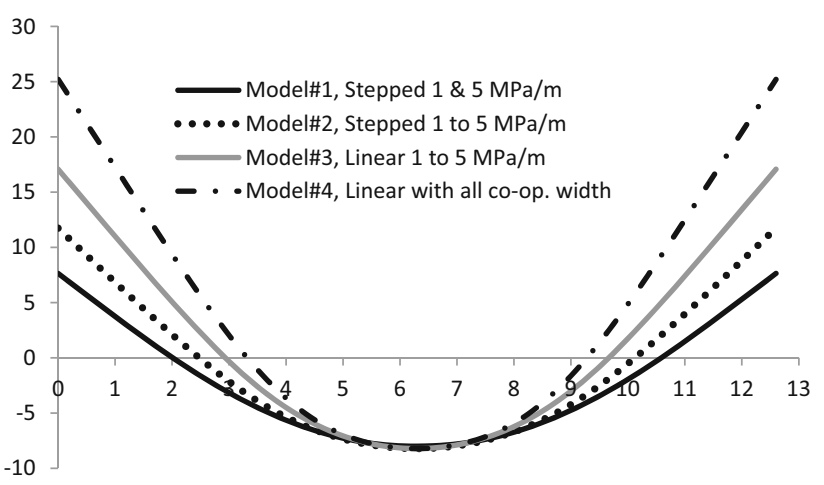

Fig. 12 Deflection profiles of the analysed slab using Swinburne FE models $(L=12.5 \mathrm{~m}, D=460 \mathrm{~mm})$

limit for slab differential deflection (SDD) and the section actual yield strength $(\mathrm{My}=42 \mathrm{kN} . \mathrm{m})$, it can be seen that the analysed slab is generally more vulnerable to failure due to excessive deflection than strength inadequacy (yielding). It should be noted that in the results shown in Fig. 12, the effect of creep is not included. Creep effect may be considered as suggested later in this study.

By comparing the results corresponding to Model 2 against the reference model (Model 1) in Fig. 3, it could be seen that the analysed slab sustains more deflection in Model 2 which could be attributed to the history of loading (heaving). It is noted that at $\mathrm{Ym}=50 \mathrm{~mm}$, both models have the same boundary profile (heave shape) and the same soil stiffness profile. However, the slab in Model 2 endures some cracking corresponding to growing heave with decreasing stiffness magnitude. That would be translated into having a softer, non-linearly responding slab (at least in part) by the time the heave height reaches $\mathrm{Ym}=50 \mathrm{~mm}$. The bending moment demand is also greater in Model 2 as compared with Model 1 (see Fig. 13).

By further refining the stiffness profile from a stepped transition to a more realistic linear transition, as discussed earlier and shown in Figs. 4 and 5, respectively, the deflection demand imposed on a given slab is further increased. This could be seen if Model 3 is compared against Model 4 in Fig. 12 (all other parameters are the same in the two models). This is explained by the fact that in general the stiffer is the soil; the lesser is the penetration of slab into heaving soil (soil depression) and the greater is the deformation demand on slab. This might be better understood if one considers that the moisture-induced heaving action of soil, which can push against the slab in an upward direction, has to be transformed into a combination of (1) slab differential deflection, (2) the depression of soil under the slab which is also referred to as slab penetration into soil, and (3) any uniform movements of entire slab depending on the slab size, magnitude of 
Fig. 13 Bending moment profiles/envelopes of the analysed slab as obtained from Swinburne FE models

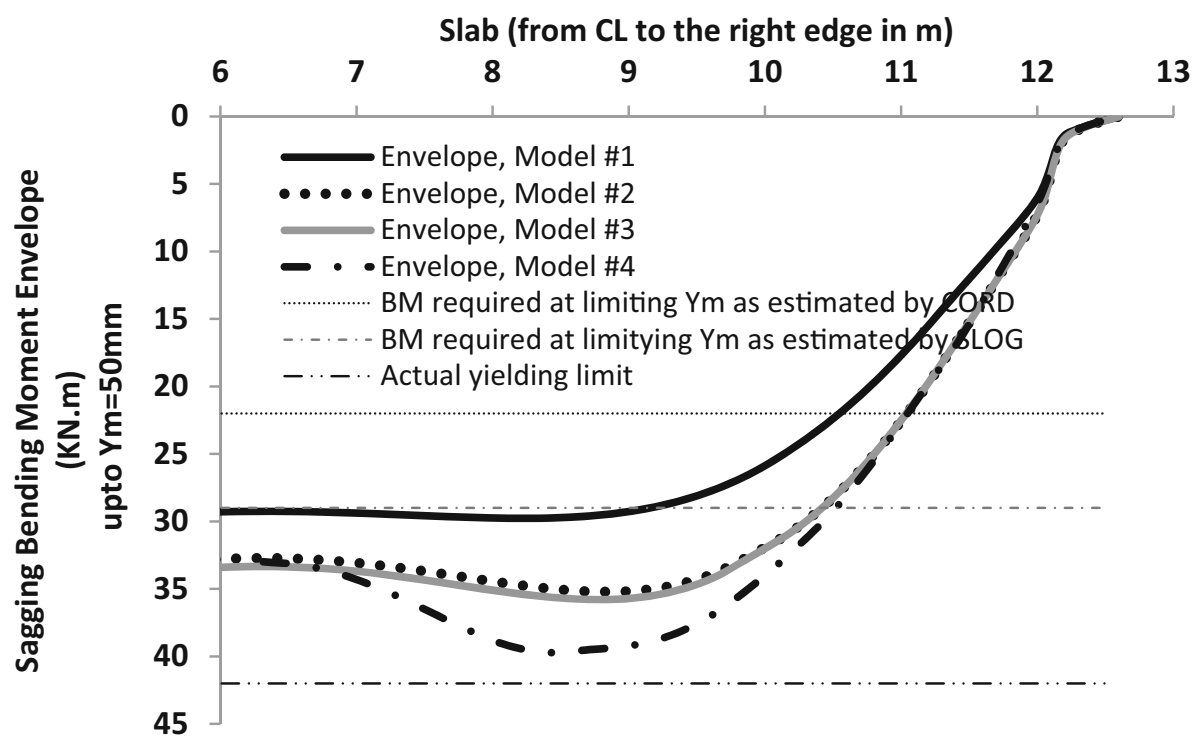

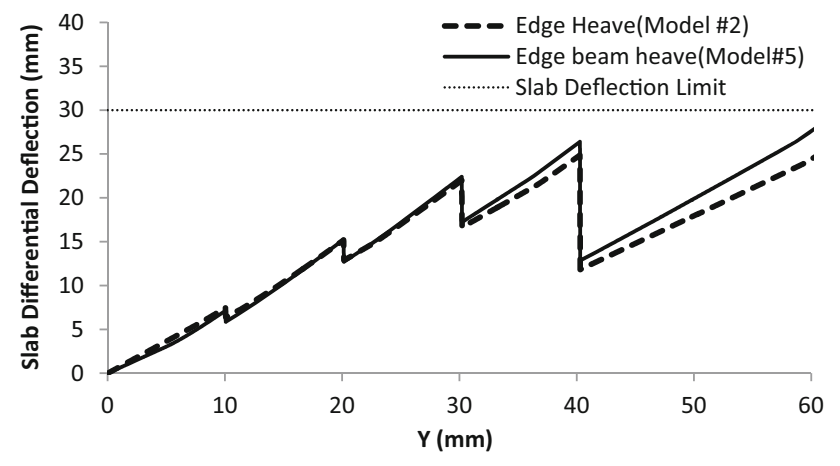

Fig. 14 The history of peak demand on slab (i.e. differential deflection) with developing mound in Models 2 and 5

restraining gravity loads and etc. There is usually a tradeoff between the three components.

Increasing the effective contact area between soil and slab as considered in Model 4 compared with previous models is seen to further increase the deflection and bending moment demands imposed on slab. By more realistic representation of the expected contact area, the tributary area of the soil represented by each spring is increased. This would mean stiffer springs which in turn put more demand on slab.

Figure 14 compares the slab differential deflection changes as a function of mound height (Y) for Models 2 and 5. The results suggest that the two models are comparable with Model 5 being slightly more demanding on the slab despite the edge beam heave assumption corresponding to Fig. 11c. This suggests the vulnerability of the standard slabs to concentrated heaving. However, it is to be noted that the stiffening effect of adjacent beams would have a desirable effect which could partly offset the additional deformation expected due to creep.
Figure 14 also demonstrates that the combination of maximum mound height $(\mathrm{Ym}=50)$ and soft soil stiffness of $1 \mathrm{MPa} / \mathrm{m}$ does not necessarily make the most critical scenario as far as the demands on slab are concerned. The results shown in this figure suggest that the differential deflection demand on the analysed slab could be even more severe at the heave height of $Y=40$ coupled with relevant soil stiffness.

In the absence of dedicated research on the creep effect for waffle slab on reactive soil, it is suggested that the estimated slab differential deflection presented by the models in this study be scaled up by a factor of 1.5. This is approximately as conservative as the measure proposed by AS2870-11 which recommends an interaction analysis using a reduced modulus of elasticity $(\mathrm{Er}=15,000 \mathrm{MPa})$ for N20 concrete. Considering that N20 concrete has the mean Ec value of 22,500 MPa as per AS3600-2009 [9], the $\mathrm{Er} / \mathrm{Ec}$ would be 0.67 . A reduction in modulus of elasticity, by a factor of 0.67 , suggests an increase in slab deflection $\Delta$ by a factor of 1.5 as the two parameters are inversely related. This is evident in elastic analysis in general and could also be seen in the simplified design equation as proposed by Walsh as is given below:

$E I=\left(1-C_{2}\right) \frac{w \cdot L^{4}}{96 \Delta}$.

It should be mentioned that the above creep factor is not to be applied to the required bending moment as it is believed that the presented BM envelopes represent a realistically conservative ultimate demand. Employing a reduced $\mathrm{E}$ value would mean that the history of interaction, extent of cracking and bending moment development is altered to some extent. This technique is generally translated into an increased deflection (which is favourable 
considering the creep consideration) and underestimating the bending moment demand if the middle section of the beam is in contact with ground before yielding.

\section{Summary/conclusions}

A comprehensive inelastic FE model was developed in OpenSees for the analysis of waffle slabs on reactive soil (edge heave condition).

The developed model simulates the action of expansive soil pushing against the slab. It records the history of soilslab interaction, while the swelling soil under the slab edges grows vertically and progresses horizontally under the slab.

Several models were developed to study the implication of typical assumptions conventionally employed in soilslab interaction analysis. This includes soil stiffness profile, effective contact between soil and slab and so on.

It was demonstrated that the assumption of a singlestiffness profile (i.e., $1 \mathrm{MPa} / \mathrm{m}$ for the soft soil and $5 \mathrm{MPa} /$ $\mathrm{m}$ for the hard soil) corresponding to ultimate mound height is not necessarily conservative. In this study, gradual mound development and corresponding soil stiffness reduction were modelled to simulate the history of soilslab interaction.

It was demonstrated that the assumption of stepped transition from soft to hard soil is not conservative, and a linear transition may be considered as a more realistic and conservative substitution.

It was demonstrated that the effective contact is a key factor in interaction analysis. It is recommended that the 200-mm co-operative width be considered on both sides of all internal and edge beams.
In the analyses presented here, the effects of structural stiffness in restraining the slab movement are not considered. Optimal design of waffle slabs would require the inclusion of structure into interaction analysis (i.e. a soilslab-structure interaction analysis).

Acknowledgments This research is funded by ARC linkage Project LP100200306. The authors gratefully acknowledge the financial and technical support provided by the collaborating organisations, namely; Victorian Building Authority (VBA), Victorian Office of Housing (OoH), Foundation and Footings Society of Victoria (FFSV), Association of Consulting Structural Engineers Victoria (ACSEV) and Housing Engineering Design and Research Association (HEDRA).

\section{References}

1. Standard Australian (2011) AS 2870-11. Residential slabs and footings, Sydney

2. Lytton RL (1970) Analysis for design of foundations on expansive clay. Proc of Symposium on Soils and Earth Structures in Arid Climates, Institution of Engineers Australia, Adelaide 29-37

3. Mitchell PW (1980) The structural analysis of footings on expansive soil. ASCE, Expansive Soils

4. Walsh P, Cameron D (1997) The design of residential slabs and footings. HB 28, Standards Australia, Sydney, Australia

5. Payne D, Cameron D (2014) The Walsh method of beam-onmound design from inception to current practice. Aust J Struct Eng 15(2):177-188

6. Karunarathne A, Sivanerupan S, Gad E, Disfani M, Rajeev P, Wilson J, Li J (2014) Field and laboratory investigation of an expansive soil site in Melbourne. Aust Geomech J 49(2):85-94

7. Lu N, Kaya M (2014) Power law for elastic moduli of unsaturated soil. J Geotech Geoenviron Eng 140(1):46-56

8. Walsh PF, Walsh S (1986) Structure/reactive-clay model for a microcomputer, CSIRO Division of Building Research

9. Standard Australian (2009) AS 3600. Concrete Structures, Sydney 